\title{
Assessment of the customized birth weight formula in a low risk Indian population
}

\section{Dipti Das*, K. Aparna Sharma, Vatsla Dadhwal, Dipika Deka, Perumal Vanamail}

Department of Obstetrics and Gynecology, All India Institute of Medical Sciences, New Delhi, India

Received: 01 July 2019

Accepted: 05 August 2019

\section{*Correspondence:}

Dr. Dipti Das,

E-mail: diptidas19@gmail.com

Copyright: (c) the author(s), publisher and licensee Medip Academy. This is an open-access article distributed under the terms of the Creative Commons Attribution Non-Commercial License, which permits unrestricted non-commercial use, distribution, and reproduction in any medium, provided the original work is properly cited.

\begin{abstract}
Background: Birth weight is probably the single most important factor that affects neonatal mortality, infant and childhood morbidity in both developed and developing countries. Objective of the study was to formulate a model for prediction of fetal weight at term based on individualized fetal growth parameters.

Methods: 131 participant low risk gravidas were enrolled into the study. The participants underwent an ultrasound 7 days prior to delivery. All fetal variables of growth of a random 100 participants were incorporated in an equation derived using multiple regressions to predict birth weight at term. The new equation was then prospectively applied to another 31 pregnant women for validation. The diagnostic performance of the new regression formula was then compared to the Hadlock formula.

Results: The customised birth weight formula predicted a higher accuracy with MPE \pm SD of $0.790 \pm 9$. compared to the Hadlock formula with MPE \pm SD $-4.42 \pm 8.73$. The new formula also explained a greater variance in birth weight of $56 \%$ compared to the Hadlock formula of $49 \%$.

Conclusions: The new model based on individualized fetal growth parameters recognizes the capacity to modulate an accurate final birth weight, thus emphasizing the need for customized population specific birth weight formulas.
\end{abstract}

Keywords: Customized, Estimated fetal weight, Fetal biometry

\section{INTRODUCTION}

Accurate fetal growth assessment is essential to decrease perinatal mortality and morbidity. An estimated 23.3 million infants (19.3\% of live births) were born small for gestational age in low and middle income countries. ${ }^{1}$ The incidence of fetal macrosomia significantly varies across geographic regions with a range of $0.5 \%$ to $15 \%$ in 23 developing countries in Africa, Asia and Latin America. ${ }^{2}$ Growth restricted fetuses are susceptible to hypoxia, fetal distress, perinatal death and neurological sequelae whereas macrosomia has increased rate of cesarean delivery, post partum hemorrhage, vaginal lacerations and the neonates may develop shoulder dystocia ${ }^{3-6}$
Sonographic assessment of the fetus and estimation of its weight have become part of routine practice in obstetrics. Many formulas have been published, most of them involving combinations of several biometric parameters. The commonly used reference ranges were based on single populations largely from industrialized countries with uncertain applicability in a world of ethnic variation. $^{7-11}$ Nevertheless the two dimensional parameters provide weight estimates with errors up to $20 \%$ when compared to the actual weight - indicating a general lack of accuracy. ${ }^{8-11}$

Inspite of careful antenatal surveillance the burden of failure to detect growth abnormalities in a low risk 
population is undeniable. This led us to hypothesize a formula based on the individualized growth parameters that might increase the accuracy of weight estimation.

The aim of the present study was therefore to develop a new customized formula for estimating weight in fetuses and compare the new regression formula with commonly used Hadlock's equation. ${ }^{10}$

\section{METHODS}

This was a prospective cohort observational study conducted in the Department of Obstetrics and Gynaecology, All India Institute of Medical Sciences, New Delhi from December 2014 to November 2016.

The study was approved by the institute ethics committee on $1^{\text {st }}$ April, 2015. Informed consent was taken from all the participants.

One hundred and thirty one women were recruited to the study after 36 weeks period of gestation.

The inclusion criteria were a singleton live pregnancy with absence of structural or chromosomal malformations. Fetal age was determined by the first day of the last normal menstrual period and confirmed by either first or early second-trimester ultrasound scans.

An ultrasound examination with complete biometric parameters; Biparietal Diameter (BPD), Head Circumference (HC), Abdominal Circumference (AC) and Femur Length (FL) was measured. The scan was repeated if the patient did not deliver within 7 days. Data on the gestational age at birth, birth weight and sex of the newborn and clinical were collected from the mother's hospital record.

All ultrasound examinations were performed transabdominally, with a VOLUSONTM E8 (BT 13.5, GE HEALTHCARE, USA) RAB 4-8L probe by a specialist who had experience in ultrasound imaging.

The coefficient of determination $\left(\mathrm{R}^{2}\right)$ was used to indicate the degree of birth-weight prediction variability that could be explained by each variable and model. Stepwise regression analysis was used to assess whether clinical parameters had any influence on the weight estimation, retaining variables with $\mathrm{p} \leq 0.05$. In addition, multivariable polymonial regression analysis was carried out with birth weight (BW) (in grams) as the dependent variable and sonographic parameters (BPD, HC, AC, FL; all in centimeters) as independent variables on the data of 100 fetus. A forward selection procedure was employed to obtain the best-fit formula to calculate the estimated fetal weight $(\mathrm{EFW})$.

$\mathrm{EFW}=4263.224+115.889 * \mathrm{BPD}+41.616 * \mathrm{HC}+112.147 *$ $\mathrm{AC}+185.553 * \mathrm{FL}$. The cut-off value for selection or removal of covariates was a $p$ value of 0.05 . The remaining 31 were used to validate the new regression formula.

For evaluation of performance, the new formula was compared with the widely accepted Hadlock formula. ${ }^{10}$

$\mathrm{BW}=(\log 10 \mathrm{EFW}=1.335-(0.0034 \mathrm{AC} \times \mathrm{FL})+0.0316$

$\mathrm{BPD}+0.0457 \mathrm{AC}+0.1623 \mathrm{FL})$

The accuracy of the best fit formula (EFW) was assessed by calculating the mean percentage error (MPE: (|EFW$\mathrm{BW} \mid) / \mathrm{BW} \times 100)$.

\section{RESULTS}

The 131 participants enrolled in the study was randomly divided into two parts for model formulation $(n=100)$ and validation purpose $(n=31)$.

The clinical data of the participants are shown in Table 1. The baseline characteristics of the formulating and the validation group did not vary significantly from each other.

The mean values of the four sonographic parameters and their first order correlations with birth weight were investigated and presented in table 2. None of the parameters had any significant influence on the birth weight.

We further analysed the birth weight prediction variability of each parameter using coefficient of regression. Table 3 demonstrates that of all parameters, abdominal circumference explained the maximum variance of $37.5 \%$

Table 1: Clinical parameters of the participants.

\begin{tabular}{|l|clc|}
\hline & Formulating group $(\mathbf{n = 1 0 0})$ & Validating group $(\mathbf{n = 3 1})$ & p value \\
\hline Age (years) & $28.83 \pm 4.3$ & $30.97 \pm 5.4$ & 0.025 \\
\hline BMI $\left(\mathrm{kg} / \mathrm{m}^{2}\right)$ & $28.29 \pm 3.1$ & $28.94 \pm 4.1$ & 0.358 \\
\hline Gestation of scan (weeks) & $38.09 \pm 0.9$ & $38.38 \pm 0.9$ & 0.165 \\
\hline Gestation at delivery (weeks) & $38.48 \pm 0.9$ & $38.66 \pm 0.9$ & 0.328 \\
\hline Birth weight (grams) & $3039.20 \pm 42$ & $3226.97 \pm 49$ & 0.038 \\
\hline
\end{tabular}


Table 2: Multilinear regression of the ultrasonographic parameters in the population.

\begin{tabular}{|lll|}
\hline Parameter & Mean \pm SD & p value \\
\hline BPD & $9.21 \pm 0.36$ & 0.63 \\
\hline HC & $32.16 \pm 1.49$ & 0.80 \\
\hline AC & $32.19 \pm 2.07$ & 0.61 \\
\hline FL & $7.06 \pm 0.40$ & 0.35 \\
\hline
\end{tabular}

Table 3: Contribution of parameters explaining the variance in birth weight.

\begin{tabular}{|ll|}
\hline Parameter & $\mathbf{R}^{2}$ \\
\hline BPD & 0.109 \\
\hline HC & 0.196 \\
\hline AC & 0.375 \\
\hline FL & 0.09 \\
\hline BPD+ FL & 0.172 \\
\hline
\end{tabular}

Table 4: Performance comparison of the formulas.

\begin{tabular}{|l|ll|}
\hline Formula & MIPE \pm SD & $R^{2}$ \\
\hline Hadlock $^{\mathbf{1 0}} \log 10 \mathrm{EFW}=1.335-(0.0034 \mathrm{AC} \times \mathrm{FL})+0.0316 \mathrm{BPD}+0.0457 \mathrm{AC}+0.1623 \mathrm{FL}$ & $-4.42 \pm 8.73$ & 0.493 \\
\hline Best fit formula $\mathrm{EFW}=-4263.224+115.889 * \mathrm{BPD}+41.616 * \mathrm{HC}+112.147 * \mathrm{AC}+185.553 * \mathrm{FL}$ & $0.790 \pm 9.11$ & 0.562 \\
\hline
\end{tabular}

Combining the parameters of the formulating group and use of multiple regression coefficients to calculate optimal coefficients yielded the following best fit formula.

Estimated birth weight $(\mathrm{EFW})=-4263.224+115.889 *$ $\mathrm{BPD}+41.616 * \mathrm{HC}+112.147 * \mathrm{AC}+185.553 * \mathrm{FL}$. The screening performance of the newly derived formula was compared to the widely used Hadlock formula.10 Table 4 shows the customised birth weight formula predicted a higher accuracy with $\mathrm{MPE} \pm \mathrm{SD}$ of $0.790 \pm 9$. compared to the Hadlock formula with MPE \pm SD $-4.42 \pm 8.73$. The new formula also explained a greater variance in birth weight of $56 \%$ compared to the Hadlock formula of $49 \%$.

\section{DISCUSSION}

A customized standard formula better projects the adverse pregnancy outcome at both ends of the fetal size spectrum and increases the obstetrician's confidence in appropriate assessment of growth. Over 50 formulae for EFW have been published by various authors, mainly derived from industrialized population and these available values are however typically associated with random error ranging from $8.1-11.8 \% .^{12}$

The present study devised a population specific customized formula using the two dimensional fetal parameters in an attempt to decrease the random errors. The study depicted that the birth weight attributability increased from $49 \%$ to $56 \%$ on customization of the formula. The customised birth weight formula predicted a higher accuracy compared to the Hadlock formula with MPE \pm SD $(0.790 \pm 9.11,-4.42 \pm 8.73)$ respectively.

The study complements the findings of previously reported studies. Lee et al reported an improvement in $\mathrm{MPE} \pm \mathrm{SD}$ from $9 \pm 9$ to $-0.1 \pm 9.8$ on customization of the original Hadlock formula as per the population. However both formulas had similar prediction of attributability of birth weight. ${ }^{10,13}$ Bennini et al studied that formulas derived from the population served to improve the accuracy. The MPE \pm SD with Hadlock formula was $-12.43 \pm 15.3$ and for the population specific formula was $2.73 \pm 8.3 .{ }^{14}$ Yang et al did not see any additional benefit of modifying the formula according to the population as the MPE \pm SD $(-3.53 \pm 6.51,-3.71 \pm 5.67)$ for the original and modified formula respectively were found to be alike. ${ }^{15}$

The study was also suggestive for proper application of the formula, it is advisable to take into account the abdominal circumference, as step-wise regression analysis found it to have the highest accountability in fetal weight prediction. The study was not without its own set of weaknesses. The study did not take into account of inter and intra observer variability which has due importance in the performance of any ultrasonographic measurements. The formula, though population specific has not accounted for the maternal height, weight, parity or ethnicity. The sample size was also not large enough to study the impact of growth restricted fetuses, macrosomia, oligoamnios and polyhdramnios. The formula was also did not extrapolated as only term patients were included, which would have further validated the study.

\section{CONCLUSION}

The findings of the study imply that the equation is robust to predict birth weight based on population specific fetal biometric parameters that are outside the bounds of original prediction equations. However further research is required which would address the limitations of the study.

\section{ACKNOWLEDGMENTS}

Authors would like to thank Department of Obstetrics and Gynaecology, All India Institute of Medical Sciences, New Delhi for their support during study. 
Funding: No funding sources

Conflict of interest: None declared

Ethical approval: The study was approved by the Institutional Ethics Committee

\section{REFERENCES}

1. Lee AC, Kozuki N, Cousens S. Estimates of burden and consequences of infants born small for gestational age in low and middle income countries with intergrowth-21st standard: analysis of cherg datasets. BMJ. 2017;358:3677.

2. Koyanagi A, Jun Z, Amarjargal D, Fumi H, Kenji S, Joao PS. Macrosomia in 23 developing countries: an analysis of a multicountry, facility-based, cross sectionalsurvey.Lancet. 2013;381(9865):476-483.

3. Moraitis AA, Wood AM, Fleming M, Smith GC. Birth weight percentile and the risk of term perinatal death. Obstet Gynecol. 2014;124(2):274-83.

4. Longo S, Bollani L, Decembrino L. Short-term and long-term sequelae in intrauterine growth retardation (IUGR). J Maternal Fetal Neonatal Med. 2013;26(3):222-5.

5. Kolderup LB, Laros RK, Musci TJ. Incidence of persistent birth injury in macrosomic infants association with mode of delivery. Am J Obst Gyn. 1997;177(1):37-41.

6. Christoffersson M, Rydhstroem H. Shoulder dystocia and brachial plexus injury: a population-based study. Gyn Obstetric Investigation. 2002;53(1):42-7.

7. Campbell S, Wilkin D. Ultrasonic measurement of fetal abdomen circumference in the estimation of fetal weight. BJOG: An Int J Obst Gyn. 1975;82(9):689-97.

8. Hadlock F, Harrist R, Carpenter R, Deter R, Park S. Sonographic estimation of fetal weight. The value of femur length in addition to head and abdomen measurements. Radiol. 1984;150(2):535-40.
9. Warsof SL, Gohari P, Berkowitz RL, Hobbins JC. The estimation of fetal weight by computer assisted analysis. Am J Obst Gyn. 1977;128(8):881-92.

10. Hadlock FP, Harrist R, Sharman RS, Deter RL, Park SK. Estimation of fetal weight with the use of head, body, and femur measurements a prospective study. Am J Obst Gynecol. 1985;151(3):333-7.

11. Woo J, Wan C, Cho K. Computer-assisted evaluation of ultrasonic fetal weight prediction using multiple regression equations with and without the fetal femur length. J Ultrasound Med. 1985;4(2):65-7.

12. Melamed N, Yogev Y, Meizner I, Mashiach R, Pardo J, Haroush A. Prediction of fetal macrosomia: effect of sonographic fetal weight-estimation model and threshold used. Ultrasound Obst Gynecol. 2011;38(1):74-81.

13. Lee W, Deter RL, Ebersole JD, Huang R, Blanckaert $\mathrm{K}$, Romero R. Birth weight prediction by threedimensional ultrasonography: fractional limb volume. J Ultrasound Medicine. 2001;20(12):128392.

14. Bennini J, Marussi E, Barini R, Faro C, Peralta C. Birth - weight prediction by two-and three dimensional ultrasound imaging. Ultrasound Obst Gynecol. 2010;35(4):426-33.

15. Yang F, Leung KY, Hou YW, Yuan Y, Tang MY. Birth-weight prediction using three-dimensional sonographic fractional thigh volume at term in a Chinese population. Ultrasound Obst Gynecol. 2011;38(4):425-33.

Cite this article as: Das D, Sharma K, Dadhwal V, Deka D, Vanamail P. Assessment of the customized birth weight formula in a low risk Indian population . Int J Reprod Contracept Obstet Gynecol 2019;8:3722-5. 